\title{
Efficiency Scores for Egyptian Public Sector Industries
}

\author{
Ibrahim Mosaad Elatroush \\ Department of Economics, Tanta University, Egypt
}




\title{
Efficiency Scores for Egyptian Public Sector Industries
}

\author{
Ibrahim Mosaad Elatroush* \\ Department of Economics, Tanta University, Egypt
}

\begin{abstract}
This paper Spotlights technical efficiency estimates using pooled data for the Egyptian public manufacturing firms from 2006 to 2011 via SFA technique. Results exhibit great irregularity among industries and within the same industry. Results also show that firm's size, age, infrastructure conditions, exchange rate, and access to finances clearly affect efficiency scores since they are suffering from deliberate governmental ignorance.
\end{abstract}

Keywords: Public sector; Efficiency; SFA; manufacturing Industries JEL classification: C23; C51; D24; L67

\footnotetext{
* Tanta University, Faculty of commerce, 18 Said Street, Tanta, Egypt. Email: ibraelatroush@hotmail.com
} 


\section{Introduction}

In 1922, under the slogan of encouraging the Egyptian products by Talaat Harb who was the main contributor of the establishment of the first Egyptian bank owned and operated by Egyptians (Banque Misr; the bank of Egypt). Afterwards, several ventures are established to create a national modernized industry. In 1927, Talaat Harb started to establish a first national industry in the country in an accurate methodical base by establishing the biggest firm for yarn and cotton weaving in the Middle East at El-Mahalla El-Kubra. A sequence of firms followed Misr El-Mahalla was set up such as Misr Kafr ElDawwar, Misr Helwan, etc. These firms were considered as bases for textile and apparel industry and institutions for generating practical expertise in the industry. In a parallel way, state capitalists set the foundations of other industries such as glass and sugar.

During the 1950s, the government decided to establish a series of firms' that cover different manufacturing activities. In 1954, the Egyptian iron and steel company was established and then fertilizers, chemicals, oil refining, and pharmaceutical corporations were set up. By the end of July 1961, large private entities better were nationalized and set under the authority and supervision of Egyptian holding corporations. Small units were excluded from nationalization 
whether they are spread across the country or concentrated in industrial zones. Thus, public entities played the role of leading industries and conferred fund by the government. Generally, the manufacturing sector was affected by prevailed thoughts in this era that aimed to satisfy low-income people's needs whether from public or private sector firms.

Under the protectionism policy, which was the main aspect in international trade until the beginning of the ninetieths where economic reform policies were adopted, such as gradual prices liberalization, structural adjustments and widens private ownership. Unfortunately, the privatization program was managed in a wrong way in which the government started to sell profitable public units and stopped restructuring instable ones. The consequences of those wrong policies- stop injecting new investments in the sector, stop upgrading machinery and equipment, getting rid of skilled laborhave driven the sector to productivity slowdown.

\section{The Model}

A Cobb-Douglas form for stochastic production frontier is used. The time-varying inefficiency effects method, proposed by Battese and Coelli (1992), is employed in the model and the Cobb-Douglas model is defined by: 


$$
Y_{i t}=f\left(x_{i t}\right)
$$

(1)

$$
Y_{i t}=B_{0}+\sum B x_{i t}+\varepsilon_{i t}
$$

(2)

Where the error term is a compound error

$$
\varepsilon_{i t}=v_{i t}-u_{i t}
$$

The $u_{i t}$, the inefficiency term, is defined as:

$$
u_{i t}=\eta_{t} u_{i} \quad i=1,2, \ldots, 434 ; t=1,2, \ldots, 6 \quad \text { and }
$$

$\eta_{t}=\{\exp [-\delta(t-T)]\}$

(5)

Output $\left(Y_{i t}\right)$ is the natural logarithm of total value of the industrialized output rated by net sales for $i$ firm, $t$ year in Egyptian pounds 2006 constant prices. Inputs $\left(X_{i t}\right)$ are the natural logarithm of total value of the inputs used in the production process $i$ firm, $t$ year in Egyptian pounds 2006 constant prices. The factors of production are combined into three categories in which labor $\left(L_{i t}\right)$ represents the natural logarithm of total paid wages per year 2006 constant prices (denoted $\left.x_{1}\right)$, materials $\left(M_{i t}\right)$ are the natural logarithm of total costs of purchased raw materials during the year 2006 constant prices (denoted $x_{2}$ ) and 
capital $\left(K_{i t}\right)$ denotes the natural logarithm of expenditures on electricity, fuel and lubricants, maintenance, repairs of capital goods, rents of buildings and machinery, machinery upgrading...etc. as a proxy of capital during the year (denoted $\left.x_{3}\right)$.

$\varepsilon_{i t}$ are the compound error term including; $v_{i t}$ the two-sided "noise" component of the error term and $u_{i t}$ as the inefficiency term. The $v_{i t}$ is assumed to be independently and identically distributed as $N\left(0, \sigma_{v}{ }^{2}\right)$ and $u_{i t}$ is assumed to be independently and identically distributed nonnegative random variables as $N^{+}\left(0, \sigma_{u}{ }^{2}\right)$. Both $v_{i t}$ and $u_{i t}$ is distributed independently of each other, and regressors.

$\delta$ is a parameter that acts significant role in the behavior of technical efficiency (TE) over time. Battese and Coelli (1992) referred that if $\delta>$ $0, T E$ rises at a decreasing rate, if $\delta<0 T E$ declines at an increasing rate and if $\delta=0$, then $T E$ remains the same. Then maximum-likelihood estimates of parameters are obtained via LIMDEP software (Greene). After obtaining $T E$ scores, they are regressed against the following regressors:

a. Firm's size: it has four values; zero for small, one for medium, two for large and three for extra-large ones. 
b. Firm's age is categorized in two groups; new for firms less than 30 years old and old for more than 30 years because the new firms are established during the 1980s. Values zero and one are given for new and old firms.

c. The infrastructure conditions (INC) zero value means that infrastructure conditions are poor, and one value refers to good infrastructure services.

d. Exchange Rate (EXR) zero value means EXR has not any impact on production process or output prices and one means they affect input, output prices or both.

e. Access to finance (ATF) zero value means that the firm fails to obtain finance whereas value one means that the firm is capable of getting finance.

\section{Model Justification for Public sector Manufacturing Units}

An Egyptian manufacturing public unit has its own characteristics in which most of them are spread across the country in the main ten industries wherein each industry has its distinct sociological, economic and infrastructural features. Moreover, the whole ten industries are only concentrated in Cairo, Giza, and Alexandria governorates whereas other governorates barely have some of them and the distribution of industries are varied across regions. Easy access to factors of production and other 
infrastructural facilities is not evenly distributed all over the country. Regions differ widely regarding variances in available stocks of physical, human and any other characteristics such as type of machinery, range and quality of the labor force, industries' concentration etc., Social and economic infrastructure such as existence of ports, access to markets, operating a business, infrastructure facilities in which production process takes place. Measuring efficiency would not be the final goal since total competitiveness depends on a wide range of other costs, external or internal factors such as exchange rates, raw materials and energy costs, interest costs, inventory turnover, time, quality, value adding capabilities, logistics, etc. Additionally, firms vary in their sizes, age, access to finance and infrastructure conditions, which may affect efficiency scores.

Although geographical factors may play a role in technological differences among firms, such differences may also occur due to the differences in the organizational structure of a firm or by activity.

\section{Data Description}

The structure of public manufacturing sector is principally concentrated on ten industries and each one of them has its own characteristics and they are classified as follows:

1- Food and beverage

2- Textile and apparel

3- Repair and maintenance

4- Petroleum 
5- Mining and metals

7- Wooden and paper
6- Engineering

8-Chemical

9- Building and constructing products

10- Pharmaceutical

Data cover a sample of 434 public sector firms covering ten manufacturing industries' activities. Brief information will be provided about the nature of each industry and its relative importance.

Preliminary, the food and beverage industry has the biggest share of the total firms' number in which it denotes 195 firms of the total number or $45 \%$. These firms are ranged in size from small ones, which employs 4 workers to extra-large ones that hires 10029 workers. The industry includes numerous activities such as grain mills, bread industry, crude and refined sugar production, Jams and juices preparing, fruits and vegetables processing, tobacco, and other food products. It absorbs 63799 workers.

The share of ginning cotton, yarn, textile and apparel industry is $14 \%$ of total firms' number using 63241 laborers. Firms also vary in size from small size ones that hires 27 workers to extra-large ones that hires 21969 workers. This industry covers all related activities from upstream process such as ginning cotton, natural and synthetic yarn manufacturing to downstream process with wide-ranging types of final 
products of textiles and apparel such as dyeing and bleaching, weaving, numerous sorts of fabrics, home furnishing, underwear, and apparel in which the industry has thousands of differentiated products.

The repair and maintenance industry includes all activities related to all sorts of vehicles that need repair and maintenance plus building, repairing and maintaining ships and boats. The share of this industry represents $11.5 \%$ of the total number of firms and employs 12460 persons. Its size is ranged from small size firms to extra-large ones.

The share of the petroleum sector denotes around $6 \%$ of the public sector firms' number, it hires 33416 employees and ranges in size from small to large firms according to activity. It incorporates several products related to oil industry such as crude oil extract, oil refining, petrochemicals, gasoline, petrol stations, roadbed materials, lubricants and other petrol products.

The mining and metals industry encompasses actions such as crude phosphate extract, iron mining, metal ores, molten iron, coke extract, metals molten, steel chewer, aluminum manufacturing, metal ovens, steel pipes manufacturing, metal vessels, metal bridges parts and other metal products. It signifies $5 \%$ of the sector firms, ranges from medium size firms to extra large ones and absorbs 44472 employees. 
The engineering industry also denotes $5 \%$ of the sector firms' number and it comprises doings such as machinery manufacturing, tyres manufacturing, vehicles spare parts manufacturing, car assembly manufacturing, electric engines and generators, ovens manufacturing, gas, electricity and water meters, electric lamps and other products. The industry engages 18179 workers and ranges in size from medium units to extra-large ones.

The wooden and paper industry represents $4 \%$ of the total number of sector's firms and absorbs 3722 workers and produces wooden and paper products.

Similarly, the Chemical industry denotes $4 \%$ of the total number of sector's firms and employs 34792 laborers and incorporates activities such as detergents manufacturing, paints, chemical oils, fertilizers manufacturing, dried soap and soap pastes, main chemicals, pigments and other chemical products.

The share of building and constructing industry products is $3.5 \%$ of the total number of firms and it hires 39233 employees and encompasses all activities related to construction industry.

Finally, albeit the pharmaceutical industry only signifies $2 \%$ of the total number of firms, it includes large and extra-large size firms since 
it is a capital-intensive industry by nature and it produces all products related to the big pharma industry.

The population covers all sizes (small, medium, large and extra large) and they produce for local and global markets. Small and medium firms production is dedicated for local markets whereas large and extra large firms' production is dedicated for both domestic and international markets and they are fully integrated (more than one activity can be included in one firm). Furthermore, most of the firms have their own transport system to obtain the industry's factors of production and to deliver final products to clients.

This population covers the period from 2006 to 2011. These firms' activities range from fully integrated activities that cover all downstream processes to upstream processes as principal producers of some industries inputs. Raw data are obtained through the Egyptian Central Agency of Population Mobilization And Statics (CAPMAS) for a six-years panel from 2006 to 2011 including all industries inputs and outputs in current prices. Then prices are deflated to get constant prices and use 2006 as base year. Separate deflators are used for outputs, labor, capital and raw materials. The total number of observations is 2604 observations. Additionally, most theoretical information about public sector is obtained from Business Sector 
Information Center (BSIC, 2012) who is mentioned for public sector information and visits to a sample of firms in each industry across the country.

\section{Empirical Results}

The Cobb-Douglas production function form is estimated for Egyptian public manufacturing firms' data obtained from CAPMAS combined with data acquired via the BSIC to construct the five dummy variables. Separately the various categorical variables, included as regressors, are the size of a firm and its age. After predicting technical efficiency scores, they are regressed against the following regressors:

a-Firm's Size is measured by the nominal value of its intermediate inputs. It is divided into four categories: zero for small, one for medium, two for large, and three for extra large units.

b-Firm's age is measured in years and it is considered a new for firms with the age of less than 30 years old and as an old for firms with the age of more than 30 years as the new firms are established during the 1980s. Values of zero and one are given for new and old firms.

c- Infrastructure Conditions (INC): zero value means that INC conditions are poor whereas value one means that INC conditions are good. 
d- Access To Finance (ATF): zero value indicates that the firm has difficulties to ATF while value one implies that the firm is able to ATF.

e- Exchange Rate (EXR): zero value shows that the EXR doesn't have any impact on factors of production price or output prices and one value illustrates that the EXR affects input or output prices or both of them.

Table one illustrates descriptive statistics for public sector manufacturing firms' variables and dummy variables coefficients.

Table two displays the estimated MLEs for a six-years panel of the population of public sector units. The dependent variable is the output of net yearly sales for each firm evaluated in Egyptian Pounds at 2006 constant prices. The regressors are labor, materials and capital consecutively. The results reveal that the coefficients are highly significant. Despite these results, the labor factor for manufacturing public is fluctuated among industries and it will be explained exhaustively in another paper due to such differences among industries with respect to the technique of production is implemented- labor intensive or capital intensive- which entails a comparative study across industries. Overall, the Egyptian public units have distinguished characters than private units have among them; imbalance between the distribution of white and blue-collar employees in which the share of 
blue-collar represents $60 \%$ of total labor force in the sector and participates in the major portion of income. Alternatively, the whitecollar ratio does not exceed $10 \%$ of total labor force in the private sector. Moreover, the wages of labor increase for social considerations whether labor's productivity increased or decreased which kills the motivation for productive laborers, while the wage is determined in private units by laborer's productivity and this is obvious from efficiency average, which is $35 \%$. The third factor is the early pension scheme wherein its target was to reduce the number of the white-collar employees by allowing them to apply for optional retirement. Unfortunately, the opposite is happened in which the skilled bluecollar employees are retired and the gap between the white and the blue-collar increased. This lack of skilled blue-collar in most industries creates more burdens on existing workers and led to more productivity slowdown. Furthermore, deliberate and unplanned strategies for machinery upgrading are arbitrarily within firms in the same industry or among industries. Efficiency scores for firms within the same industry and within industries are varied significantly. Technical efficiency's mean is $35 \%$ with the range of less than $1 \%$ for the minimum and $89 \%$ for the maximum. 
For the food and beverage industry, the efficiency scores are varied within firms in a sole governorate and across governorates with the average of $43 \%$. The higher efficiency score is found in a large size firm of grain mill activity (Cairo Governorate) at $81 \%$ and the lowest at a small size firm of producing bread with less than $1 \%$ (Alexandria governorate).

For the textiles and apparel industry, the mean technical efficiency is $23 \%$ for industry, with high score of $69 \%$ for a yarn and textile firm (Gharbia governorate) and the lowest-less than $1 \%$-for cotton ginning firm (Qalyubia governorate). This sector represents the lowest efficiency scores among public manufacturing industries. The lowest efficiency scores are found in Qalyubia, Giza, and Cairo governorates firms. This can be mainly attributed to several reasons; the imbalance between the distribution of white and blue collar employees within firms in the industry is the highest among public industries, wages in the sector are very low relative to other sectors, the rewards for productive workers are negligible which kill the motivation for the productive workers, the retirement of skilled laborers increases the burden on unskilled workers and leads to extra productivity slowdown. The cut off training programs which is considered the main source of generating skilled labor. A lack of machinery modernization and the 
increase of raw materials prices due to cotton prices liberalization affect capital and materials variables. Alack of clear strategies to eliminate the massive amounts of inventory which has a clear impact on the production process. All these factors led banks to flinch from provide finance to the sector. Elatroush and Montes-Rojas (2011) achieve similar results for Egyptian textiles and apparel industry.

For the repair and maintenance industry, the mean efficiency score is $28 \%$ in which the lowest score of less than $1 \%$ is for a car maintenance firm that lies in Alexandria governorate and the highest score of $85 \%$ is also for an extra large firm lies in Sharqia governorate. The main reasons behind low scores in repair and maintenance industry may be ascribed to; the overstaffed labor, lack of fund to buy good quality spare parts, obsoleted equipment, and most of car maintenance firms are set to fix and repair public transportation vehicles only which led to reduce the utilized capacity in these firms.

For petroleum industry, the mean efficiency score is $45 \%$, which is highest score among public industries. The minimum score is $5 \%$ for gasoline refining firm lies in Suez governorate and the maximum score is also for petrol refining firm situated in Alexandria provenance in which the first one has outdated equipment while the other has new equipment. The oil sector firms have various techniques of production 
in which some of them have more advanced and modernized refining laboratories and the others are suffered from primitive and obsoleted refining laboratories. Additionally, the efficiency scores are varied within activities such as crude oil extract, petrol refining, gasoline, lubricants, and other petrol products.

For mining and metals industry, the mean efficiency score is $30 \%$ with the minimum of $1 \%$ is for iron mining firm (Giza) and the maximum of $69 \%$ is for metal vessels firm (Alexandria). The main reasons behind low efficiency scores in this industry are; the lack of new investments for machinery upgrading, the lack of supplies of raw materials such as coke for steel firms and the intense competitiveness especially from steel private sector firms.

The mean efficiency score for the engineering industry is $26 \%$ with the minimum of less than $1 \%$ and the maximum of $67 \%$. The same reasons for low efficiency scores in mining and metals industry can be applied for the engineering industry.

The mean efficiency score for the wooden and paper industry is $29 \%$ with the minimum of less than $1 \%$ for producing packaging paper firm and the maximum score of $84 \%$ for a wooden stationary products firm. The main causes of such low efficiency scores are: outdated machinery 
and equipment, lack of investments, lack of raw materials and oldfashioned products.

For the chemical industry, the mean efficiency score is $41 \%$ with the minimum score of $14 \%$ and the maximum of $82 \%$. The chemical industry is also considered the second public industry of high efficiency scores after the petroleum industry. The low level of efficiency is obvious in fertilizer industry in which these firms produce inefficiently due to the lack of supplies of raw materials such as natural gas, and electricity, which are considered the main factors of production for such industry. Consequently, the production cost is increased and the utilized capacity is declined. Alternatively, activities such as paints, detergents, and other chemical products have higher efficiency scores.

The mean efficiency scores for the building and constructing products industry are $25 \%$ with the minimum of $26 \%$ and the maximum of less than $1 \%$ is for the calcareous bricks extract firm and the maximum of $59 \%$ is for the ceramics and tiles industry. The same reasons can be applied for the industry such as: lack of the supplies of raw materials, obsoleted machinery, unskilled workforce plus oldfashioned designs and products. 
Finally, the mean efficiency score for the pharmaceutical industry is $27 \%$ with the minimum score of $18 \%$ and the maximum of $47 \%$. This industry is considered a capital-intensive industry in which it needs further capital for Research and Development (R\&D), and modern equipment. The main obstacle for the pharmaceutical industry is the price cap imposed by the government-for social considerations - that reduces profits and hinders capital accumulation. The ministry of health set the prices of firms' products to protect the poor as the owner of these firms. But this strategy affects significantly on firms' returns, which reflects on declining the funds for $R \& D$, and decrease efficiency scores.

Table 3 results show that regressors are significant. The size and age coefficients are significant at 5\% level, which means that the large and extra large size firms have higher efficiency scores than small ones due to the benefits from economies of scale. Firm's age can deepen its presence in markets and increase experience. Thus, old firms have more experience and existence in market than the new ones. Bahandari and Ray (2007) obtained the same results for Indian textiles industry. Lundvall and Battese (2009) have similar results for the size for the Kenyan manufacturing sector. Margono and Sharma (2006) obtained similar results for some sectors in Indonesian manufacturing industries. 
The INC, EXR, and ATC coefficients are highly significant and this may be ascribed to good infrastructure conditions improve working environment whereas bad infrastructure conditions hinder working environment and this also agrees with economic sense since firm lies (lying or which lies) in new industrial cities are gained good infrastructure conditions. The EXR coefficient is significant and this may be attributed to EXR which also has an impact on efficiency scores since some of raw materials are imported besides the variations in EXR affect firms' exports especially with fluctuations in exchange rates relative to other currencies. ATF is also significant and this may be due to some successful sectors in some public industries such as petroleum and chemicals and large size firms have more flexibility to access to finance than small size firms or inefficient industries such as textiles\& apparel and wooden \& paper industries.

\section{Conclusions}

The TE for the Egyptian manufacturing public sector firms is predicted using the Cobb-Douglas production function. Results indicate that the average TE of firms is $35 \%$ with variation in efficiency scores per firms within the same industry, within industries and within regions or governorates. Moreover, the impacts of size, age, 
INC, EXR and ATF are significant indicating that the improvement in these variables will lead to an enhancement in technical efficiency scores. Forthcoming paper will give attention to analyze efficiency scores per industry to make a comparison between pubic sector industries so as to detect similarities and dissimilarities among Egyptian manufacturing public firms. Differences in; industry's characteristics, regions, and utilized technique of production may affect efficiency scores. Thus, it may be irrelevant to measure efficiency scores for all industries together and the proper way is to estimate efficiency per industry since some industries are labor intensive and the others are capital intensive. 


\section{References}

Bahandari A, Maiti P. 2007. Efficiency of Indian Manufacturing Firms: Textile Industry as a Case Study. International Journal of Business and Economics. 6 (1): 71- 88.

Bahandari AK, Ray SC. 2007. Technical efficiency in the Indian textiles industry: A nonparametric analysis of firm-level data. WP49. Connecticut, U.S.A: University of Connecticut, Department of Economics.

Battese G, Coelli, T. 1992. Frontier production functions, technical efficiency and panel data: with application to Paddy farmers in India. Journal of Productivity Analysis, 3: 153-169.

Business sector information center (BSIC): Textiles and Apparel public firms 2001-2009.

Central Agency for Population Mobilization and Statistics (CAPMAS):

Annual industrial statistics bulletin. Several issues.

Central Bank of Egypt (CBE), 2003: The Annual Statistical Bulletin, several issues.

Lundvall K, Battese G. 2009. Firm Size, Age and Efficiency:

Evidence from Kenyan Manufacturing Firms. Journal of Development Studies. 36 (3): 146-163. 
Margono H, Sharma S. 2006. Efficiency and productivity analyses of Indonesian manufacturing industries. Journal of Asian Economics. 17 (6): 979-995.

Pestieau P. 2007. Assessing the performance of the public sector. Annals of Public and Cooperative Economics. 80(1): 133-161.

World Bank, 2006 Morocco, Tunisia, Egypt and Jordan after the end of the MFA: Impact, Challenges and Prospects. Washington, D.C.: World Bank.

Table 1: Public Sector Manufacturing Industries Summery statistics

\begin{tabular}{c|c|c|c|c}
\hline Variable & Mean & Min & Max & St.Dev \\
\hline Output & 15.5072 & 4.1202 & 23.5158 & 3.2371 \\
\hline Labor & 14.4332 & 7.7351 & 20.0090 & 0.7230 \\
\hline Materials & 10.7189 & 0.0000 & 23.9553 & 0.8522 \\
\hline Capital & 13.8100 & 2.1436 & 22.6569 & 0.8710 \\
\hline Size & 1.0366 & 0 & 3 & 1.0278 \\
\hline Age & 0.5565 & 0 & 1 & 0.4851 \\
\hline INC & 0.4753 & 0 & 1 & 0.4989 \\
\hline EXR & 0.5319 & 0 & 1 & 0.4762 \\
\hline ATF & 0.3170 & 0 & 1 & 0.4970 \\
\hline
\end{tabular}

Table2 MLE for production function in Egyptian manufacturing public firms

\begin{tabular}{ll|c|c|c}
\hline \multicolumn{2}{c|}{ Variable } & Coefficient & Standard Error & P. Value \\
\hline Constant & $\beta_{0}$ & 1.7593 & 0.3015 & 0.0000 \\
Labor & $\beta_{1}$ & 0.4817 & 0.0259 & 0.0000 \\
Materials & $\beta_{2}$ & 0.0324 & 0.0046 & 0.0000 \\
Capital & $\beta_{3}$ & 0.5605 & 0.0138 & 0.0000 \\
Year & $\beta_{4}$ & 0.0168 & 0.1812 & 0.3575 \\
\hline
\end{tabular}


Variance parameters for compound error

$\begin{array}{llll}\text { Lambda } & 1.6979 & 0.0103 & 0.0000 \\ \text { Sigma (u) } & 1.8996 & 0.1985 & 0.0000\end{array}$

Eta parameter for time varying inefficiency

Eta

$-0.0136$

0.0036

0.0001

$\underline{\text { Estimated Efficiencies }}$
Mean
Min
Max
Std. Dev.
0.3533
0.00009
0.8860
0.1962

2604 Observations.

Table3. Regression results explain TE score for Public firms via size, age, INF, ATF and EXR.

\begin{tabular}{c|c|c|c}
\hline \multirow{2}{*}{ Variables } & \multicolumn{3}{|c}{ Random Effects } \\
\cline { 2 - 4 } & Coefficient & Standard Error & P. Value \\
\hline SIZE & -0.0014 & 0.0007 & 0.0497 \\
\hline AGE & -0.0012 & 0.0005 & 0.0185 \\
\hline INC & -0.0121 & 0.0016 & 0.0000 \\
\hline EXR & -0.0124 & 0.0008 & 0.0000 \\
\hline Constant & 0.3987 & 0.01096234 & 0.0000 \\
\hline $\begin{array}{l}\text { Fixed vs. } \\
\text { Random } \\
\text { Effects }\end{array}$ & 26.17 & - & \\
(Hausman) & \multicolumn{2}{c}{6.556} & \\
\hline $\begin{array}{l}\text { Lagrange Multiplier Test } \\
\text { 0.0000 }\end{array}$ & $\mathrm{R}^{2} \%$ & & \\
\hline
\end{tabular}

- ATF is the reference Dummy. 

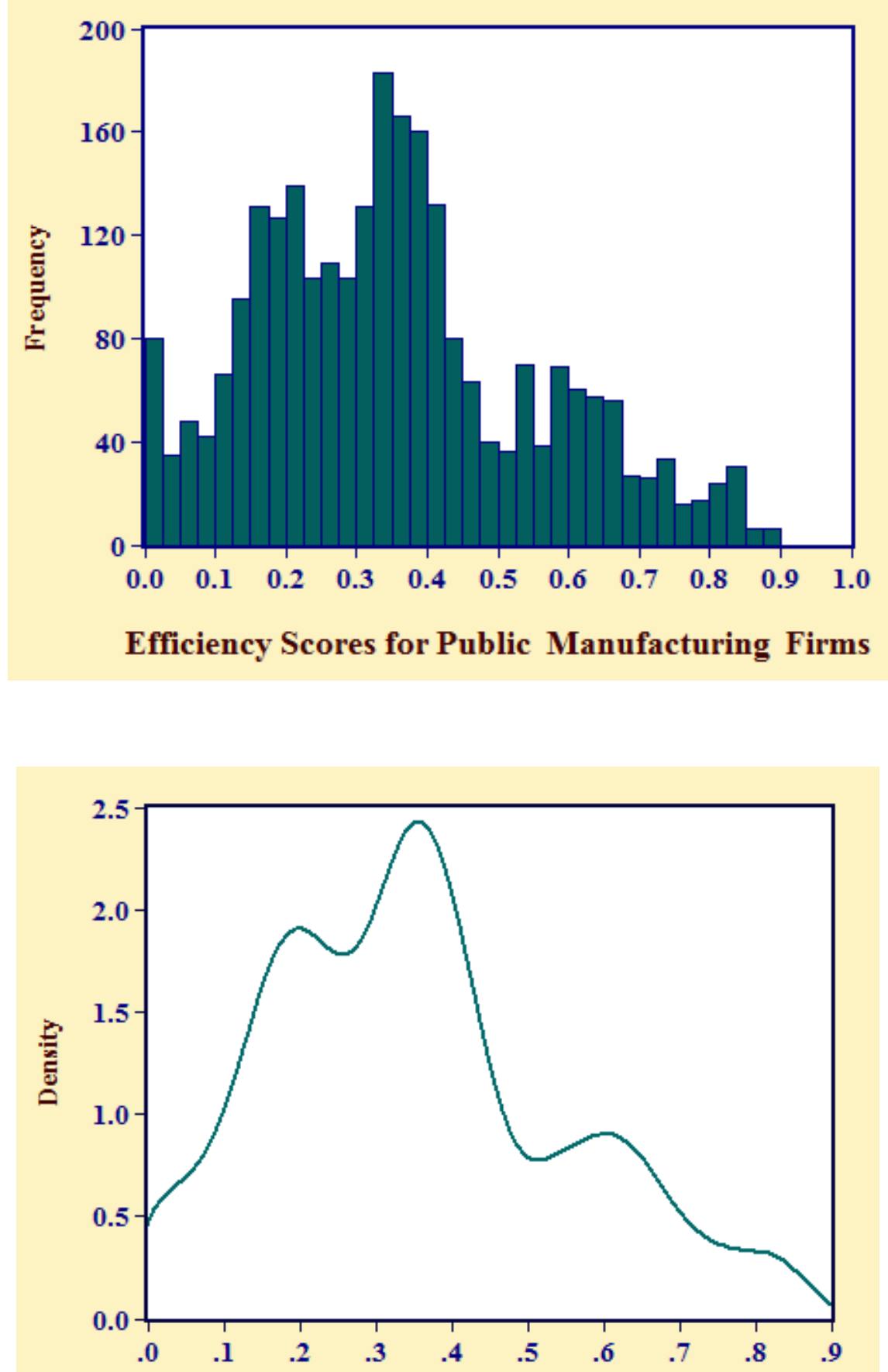

Efficiency Scores for Public Manufacturing Firms 